\title{
Las colecciones «Batihoja» y «Peregrina» del Instituto de Estudios Auriseculares (IDEA)
}

El Instituto de Estudios Auriseculares (IDEA) es una asociación cultural sin ánimo de lucro que tiene como objetivo favorecer los estudios y proyectos que conduzcan al desarrollo de las investigaciones sobre los Siglos de Oro, entendido en un sentido amplio (siglos XVI y XVII), preferentemente en el ámbito de la cultura hispánica, con un enfoque multidisciplinar (lengua, literatura, arte, historia, espiritualidad...) y siempre con criterios de la máxima calidad científica, sin excluir las actividades de difusión y divulgación. Las actividades que desarrolla se centran fundamentalmente en tres ámbitos:

- la publicación de Hipogrifo. Revista de literatura y cultura del Siglo de Oro;

- la publicación de las colecciones de libros «Batihoja» y «Peregrina»;

- y la organización de congresos internacionales, en colaboración con diversas universidades e instituciones culturales de todo el mundo.

En lo que respecta a su actividad editorial, el Instituto de Estudios Auriseculares (IDEA) ha publicado (a fecha de hoy, noviembre de 2015) un total de 17 volúmenes en su colección «Batihoja», la mayoría de los cuales se encuentran disponibles, además, en Open Access, de acuerdo con el compromiso que el IDEA tiene con el Acceso Abierto - libre y gratuito- a los resultados de investigación. Este es el listado de las publicaciones, con sus correspondientes enlaces a las versiones digitales:

- Francisco de Quevedo, España defendida, ed. de Victoriano Roncero, New York, IDEA, 2012. ISBN: 978-1-938795-87-9. [Colección Batihoja, 1]

- Ignacio Arellano, El ingenio de Lope de Vega. Escolios a las «Rimas humanas y divinas del licenciado Tomé de Burguillos», New York, IDEA, 2012. ISBN: 978-1-938795-84-8. [Colección Batihoja, 2]

- Lavinia Barone, El gracioso en los dramas de Calderón, New York, IDEA, 2012. ISBN: 978-1-938795-85-5. [Colección Batihoja, 3]

- Pedrarias de Almesto, Relación de la jornada de Omagua y El Dorado, ed. de Álvaro Baraibar, New York, IDEA, 2012. ISBN: 978-1-938795-88-6. [Colección Batihoja, 4]

- Joan Oleza, From Ancient Classical to Modern Classical: Lope de Vega and the New Challenges of Spanish Theatre, New York, IDEA, 2012. ISBN: 9781-938795-89-3. [Colección Batihoja, 5] 
- Blanca López de Mariscal y Nancy Joe Dyer (eds.), El sermón novohispano como texto de cultura. Ocho estudios, New York, IDEA, 2012. ISBN: 9781-938795-90-9. [Colección Batihoja, 6]

- Álvaro Baraibar, Bernat Castany, Bernat Hernández y Mercedes Serna (eds.), Hombres de a pie y de a caballo: conquistadores, cronistas, misioneros en la América colonial de los siglos XVI y XVII, New York, IDEA, 2013. ISBN: 978-1-938795-91-6. [Colección Batihoja, 7]

- Pedro Calderón de la Barca, Céfalo y Pocris, introd. de Enrica Cancelliere y ed. de Ignacio Arellano, New York, IDEA, 2013. ISBN: 978-1-938795-93-0. [Colección Batihoja, 8]

- Ignacio Arellano y Juan Antonio Martínez Berbel (eds.), Violencia en escena y escenas de violencia en el Siglo de Oro, New York, IDEA, 2013. ISBN: 9781-938795-92-3. [Colección Batihoja, 9]

- Francisco Santos, Periquillo el de las gallineras, ed. de Miguel Donoso Rodríguez, New York, IDEA, 2013. ISBN: 978-1-938795-94-7. [Colección Batihoja, 10]

- Alejandra Soria Gutiérrez, Retórica sacra en la Nueva España: introducción a la teoría y edición anotada de tres sermones sobre Santa Teresa, New York, IDEA, 2014. ISBN: 978-1-938795-95-4. [Colección Batihoja, 11]

- Amparo Izquierdo Domingo, Los autos sacramentales de Lope de Vega. Funciones dramáticas, New York, IDEA, 2014. ISBN: 978-1-938795-96-1. [Colección Batihoja, 12]

- Fray Pedro Malón de Echaide, La conversión de la Madalena, ed. de Ignacio Arellano, Jordi Aladro y Carlos Mata Induráin, New York, IDEA, 2014. ISBN: 978-1-938795-97-8. [Colección Batihoja, 13]

- Jean Canavaggio, Retornos a Cervantes, New York, IDEA, 2014, ISBN: 978-1938795-98-5. [Colección Batihoja, 14]

- Ricardo Fernández Gracia, La «buena memoria» del obispo Palafox y su obra en Puebla, New York, IDEA, 2014. ISBN: 978-1-938795-00-8. [Colección Batihoja, 15]

- María Fernández López (Marcia Belisarda), Obra poética completa, ed. de Vinatea Recoba, New York, IDEA, 2015. ISBN: 978-1-938795-03-9. [Colección Batihoja, 16]

- Juan Manuel Gauger, Autoridad jesuita y saber universal. La polémica cometaria entre Carlos de Sigüenza y Góngora y Eusebio Francisco Kino, New York, IDEA, 2015. ISBN: 978-1-938795-05-3. [Colección Batihoja, 17. Serie Estudios Indianos, 1] 
En cuanto a la segunda colección, la «Peregrina», su creación es más reciente y, de momento, cuenta en su haber con los siguientes libros:

- José Cadalso, Cartas marruecas, ed. de Ignacio Arellano Torres, New York, IDEA, 2015. ISBN: 978-1-938795-02-2. [Colección Peregrina, 1]

- Ricardo Fernández Gracia, Los «Dictámenes» de Juan de Palafox. «Con todos hablan en general y con cada uno en particular», New York, IDEA, 2015. ISBN: 978-1-938795-06-0. [Colección Peregrina, 2] 
